\title{
General and Maladaptive Traits in a Five- Factor Framework for DSM-5 in a University Student Sample
}

\author{
Filip De Fruyt', Barbara De Clercq', Marleen De Bolle', \\ BartWille', Kristian Markon ${ }^{2}$, and Robert F. Krueger ${ }^{3}$
}

\begin{abstract}
The relationships between two measures proposed to describe personality pathology, that is the Revised NEO Personality Inventory (NEO-PI-3) and the Personality Inventory for DSM-5 (PID-5), are examined in an undergraduate sample $(N=$ 240). The NEO inventories are general trait measures, also considered relevant to assess disordered personality, whereas the PID-5 measure is specifically designed to assess pathological personality traits, as conceptualized in the DSM-5 proposal. A structural analysis of the 25 PID-5 traits confirmed the factor structure observed in the U.S. derivation sample, with higher order factors of Negative Affectivity, Detachment,Antagonism, Disinhibition, and Psychoticism.A joint factor analysis of, respectively, the NEO domains and their facets with the PID-5 traits showed that general and maladaptive traits are subsumed under an umbrella of five to six major dimensions that can be interpreted from the perspective of the fivefactor model or the Personality Psychopathology Five. Implications for the assessment of personality pathology and the construction of models of psychopathology grounded in personality are discussed.
\end{abstract}

\section{Keywords}

Personality Inventory for DSM-5, PID-5, DSM-5, five-factor model, FFM, Revised NEO Personality Inventory, NEO-PI-3, personality disorders, general traits, assessment

Personality disorders have been traditionally conceptualized as categorical constructs, with 10 different personality disorders described on Axis-II of the fourth edition of the Diagnostic and Statistical Manual of Mental Disorders (DSM-IV; American Psychiatric Association, 2000). This categorical conceptualization has been shown to be both conceptually and empirically problematic (Clark, 2007; Widiger \& Trull, 2007) and different dimensional models were hypothesized as alternatives for personality pathology description (Widiger \& Simonsen, 2005). A number of scholars proposed various dimensional models representing maladaptive trait variance, such as the Dimensions of Personality Pathology-Basic Questionnaire (Livesley, 1990), the Schedule for Nonadaptive and Adaptive Personality (Clark, 1993), and Harkness and McNulty's Personality Psychopathology Five (PSY-5) model of clinically relevant personality domains (Harkness \& McNulty, 1994; Harkness, Finn, McNulty, \& Shields, 2012, Harkness, McNulty, \& Ben-Porath, 1995).

Other prominent trait psychologists argued that personality pathology could be also described along the dimensions of the five-factor model (FFM) of general personality (Widiger \& Mullins-Sweatt, 2009; Widiger, Trull, Clarkin,
Sanderson, \& Costa, 2002). These authors advocated the notion that the distinction between general and maladaptive traits is more a matter of degree than qualitative differences and suggested different routes to how general trait measures, such as the NEO Personality Inventory-Revised (NEO-PI-R; Costa \& McCrae, 1992), could be used for the description of personality pathology (Miller, Bagby, Pilkonis, Reynolds, \& Lynam, 2005; Miller et al., 2008; Widiger, Costa, \& McCrae, 2002). This stream of FFM research has been influential in shaping the debate for the revision of DSM-IV personality disorders (Clark, 2007; Widiger \& Costa, 2013), providing strong evidence for a dimensional representation of personality pathology in DSM-5 (Widiger, Simonsen, Sirovatka, \& Regier, 2006).

\footnotetext{
'Ghent University, Gent, Belgium

'University of lowa, lowa City, IA, USA

${ }^{3}$ University of Minnesota, MN, USA

Corresponding Author:

Filip De Fruyt, Department of Developmental, Personality and Social Psychology, Ghent University, H. Dunantlaan, 2, B-9000 Gent, Belgium. Email: Filip.DeFruyt@ugent.be
} 
Although it has been advocated that the dimensions distinguished by the FFM can serve as an overarching framework to describe personality and personality pathology (Markon, Krueger, \& Watson, 2005), there are diverging opinions on the suitability of general trait measures to assess personality pathology. First, meta-analyses of FFM and personality disorder relationships have demonstrated only partial overlap with different personality disorders (Samuel \& Widiger, 2008; Saulsman \& Page, 2004). For example, in an inpatient sample, De Fruyt, De Clercq, van de Wiele, and Van Heeringen (2006) found that the explained variance by the NEO-PI-R ranged from $45 \%$ for avoidant personality disorder to only $22 \%$ for narcissistic personality disorder. In a study with 668 patients recruited for the Collaborative Longitudinal Study of Personality Disorders, Morey and colleagues (2002) found that the borderline, avoidant, obsessive-compulsive, and schizotypal personality disorders shared a configuration of high neuroticism, low agreeableness, and low conscientiousness. The NEO-PI-R facets, however, less broadly differentiated among patients with different personality disorders, even when comorbidity of diagnoses was taken into account. Second, it has been argued that general trait measures such as the NEO-PI-R do not include enough maladaptive personality item content to adequately describe personality pathology: Experimentally manipulating items in a more clinical orientation increases overlap (Edmundson, Lynam, Miller, Gore, \& Widiger, 2011; Haigler \& Widiger, 2001; Lynam et al., 2011). Third, the FFM has been suggested to be bipolar, yet many measures of the FFM (e.g., the NEO-PI-R) are not specifically designed to measure both poles of the five domains; for example, the NEO-PI-R is pointed at Neuroticism, Extraversion, Openness to Experience, Agreeableness, and Conscientiousness, whereas Neuroticism and the negative poles of Extraversion, Agreeableness, and Conscientiousness are the more personality disorder relevant orientations (Krueger \& Eaton, 2010). Fourth, there has been debate among researchers about whether an additional factor of personality, distinct from Openness and beyond the FFM, referred to as oddity, peculiarity, or schizotypy (Watson, Clark, \& Chmielewski, 2008) is necessary to account for features of Cluster A personality disorders. Finally, a practical constraint is that measures such as the NEO-PI-R are distributed by commercial test publishers, introducing potential conflicts of interest in the discussion on the most adequate model and operationalization for personality pathology, particularly with regard to any potential connection between a specific assessment tool, sold for profit, and an official nosology, such as the DSM-5.

In response to these different issues, specific members of the Personality and Personality Disorders workgroup for DSM-5 and workgroup consultants developed a maladaptive personality inventory for DSM-5 (i.e., the PID-5, Krueger, Derringer, Markon, Watson, \& Skodol, 2012). To construct the DSM-5 model and instrument, Krueger et al. (2012) initially compiled a set of 37 traits nominated by workgroup members and consultants and deemed clinically salient in the literature. These traits were assumed to measure the four major domains of maladaptive personality variation identified by Widiger and Simonsen (2005), supplemented with an additional fifth psychoticism dimension, capturing peculiar and odd traits corresponding with features of DSM-IV Cluster A personality disorders. Items were written to assess the 37 constructs, and administered to large samples of treatment-seeking individuals from community samples. Facet scales were constructed in an iterative process using exploratory factor analysis and fitting items per facet to a single-factor confirmatory item response theory model. Item-level within-domain exploratory factor analyses showed that the initial 37 traits could be collapsed into a more manageable set of 25 traits. Krueger et al. (2012) finally demonstrated that these 25 traits could be hierarchically organized under five personality pathology factors identified as Negative Affectivity, Detachment, Antagonism, Disinhibition, and Psychoticism. The provisional mapping of facets into the domains of the $D S M-5$ trait model, based on these initial results is described in a table later in the text (Krueger et al., 2012). The proposed structure and the labels for the main dimensions in the DSM-5 trait model are close to Harkness and McNulty's PSY-5 model of clinically relevant personality domains (Harkness \& McNulty, 1994). The PSY-5's Negative and Positive Emotionality factors closely resemble the DSM-5 Negative Affectivity and Detachment factors, respectively, whereas the PSY-5 Constraint factor is conceptually (inversely) related to Disinhibition. The DSM-5 Antagonism factor shares content with PSY-5 Aggressiveness, and the Psychoticism factors from both models refer to modes and degrees of contact with reality (Harkness et al., 2012). Empirical evidence for these associations is provided by Anderson et al. (2013).

Some initial evidence on the psychometric characteristics and the replicability of factor structure of the PID-5 in U.S. undergraduate samples has recently become available (Hopwood, Thomas, Markon, Wright, \& Krueger, 2012; Wright et al., 2012), including information on the PID-5 traits to predict $D S M-I V$ personality disorders beyond an indicator of general personality pathology severity (Hopwood et al., 2012). Up until now, however, only limited information is available on how the PID-5 fits within the common framework of the FFM. Such research is warranted for the assessment field, because it is unclear at present how two prominent comprehensive trait models, the FFM with an already established position for the assessment of general traits and the DSM-5 trait model proposed to assess personality disorder traits, are connected and potentially intertwined. Recently, Thomas et al. (2012) examined in an undergraduate sample the covariance of 
PID-5 traits and domain scores from the FFM rating form (Mullins-Sweatt, Jamerson, Samuel, Olson, \& Widiger, 2006), a 30-item self-report inventory with one item for each FFM facet, showing that the five higher order factors of the conjoint exploratory factor analysis reflect the domains of the FFM. To the best of our knowledge, there are no published studies yet on the associations between the PID-5 and a comprehensive operationalization of the FFM such as the NEO-PI-R/3 (Costa \& McCrae, 1992). Although the FFM rating form is a valid measure of the FFM domains, a more fine-grained assessment (i.e., facet-level trait descriptors) is likely to be required to diagnose PD types.

In the current article, we investigate whether and how this new maladaptive personality inventory fits with the fivefactor framework as measured by the NEO-PI-3. Our objective was to examine the relationships between the PID-5 and the NEO-PI-3 to investigate whether both measures assess common underlying dimensions and whether their scales generally tap into similar (e.g., Neuroticism and Negative Affectivity, and Openness to Experience and Psychoticism) or different orientations of these dimensions.

\section{Method}

\section{Samples and Procedure}

Undergraduate psychology students $(N=240 ; n$ females $=$ 204 ; mean age $=19.78$ years; age range $=18-52$ years $)$ from Ghent University were administered the NEO-PI-3 (De Fruyt, De Bolle, McCrae, Terracciano, \& Costa, 2009; McCrae, Costa, \& Martin, 2005) and the PID-5 (Krueger et al., 2012) in the context of a series of demonstrations that were organized in the Differential Psychology course, asking students' participation about every 2 weeks in small experiments or assessments. Participation was voluntary, and students did not receive a reward or any form of course credit. Data quality in these demonstrations is usually excellent, with the majority of students participating, and feedback given at the group level in the subsequent lesson after the deadline for data administration. Inventories were administered anonymously through an online assessment platform that presented the questionnaires in a fixed order (NEO-PI-3 first, followed by the PID-5), with the possibility to stop at any time, and continue at a later stage within a 1 -week time frame.

\section{Measures}

NEO-PI-3. The authorized experimental ${ }^{1}$ version of the Flemish/Dutch NEO-PI-3 (Hoekstra \& De Fruyt, 2013) was used. The NEO-PI-3 is a more readable version of its parent inventory the NEO-PI-R (Costa \& McCrae, 1992), with a similar structure and set of 30 facets, though a number of items ( $n=37$ of a total of 240) has been slightly changed to make the inventory more appropriate for adolescents and individuals with a lower reading level. For the authorized Flemish/Dutch adaptation (Hoekstra \& De Fruyt, 2013) some minor additional changes were made relative to the Dutch NEO-PI-R item set (Hoekstra, Ormel, \& De Fruyt, 1996) to make the inventory more readable and improve internal consistency coefficients for a number of facets. The NEO-PI-3 was chosen because we wanted to use the most recent version of this FFM operationalization that will replace the NEO-PI-R in due time across the globe. De Fruyt et al. (2009) recently demonstrated in a cross-cultural study in 25 different languages that the NEO-PI-3's psychometric properties resemble those of the parent inventory. They further demonstrated that scale means for both domains and facets were directly comparable with those obtained with the NEO-PI-R, suggesting that the same norms can still be applied. With respect to the replicability of the NEO-PI-R factor structure, it is important to recall that in Germanic languages (Flemish, Dutch, and German), two NEO facets usually are primarily loading on another factor than in U.S. data. Assertiveness (E3) often has its primary (negative) loading on Neuroticism (with a substantial secondary loading on Extraversion), whereas Impulsiveness (N5), primarily loads the Extraversion factor, with a secondary loading on Neuroticism (see De Fruyt, Mervielde, Hoekstra, \& Rolland, 2000 , for a discussion of these patterns).

PID-5. The PID-5 has 220 items presented with four response options of "Very false or often false," "Sometimes or somewhat false," "Sometimes or somewhat true," and "Very true or often true." Items assess 25 trait scales, corresponding with 25 specific personality pathology constructs. The provisional positioning of these constructs within the $D S M-5$ overarching structure of Negative Affectivity, Detachment, Antagonism, Disinhibition, and Psychoticism is described in a table later in the text (derived from Krueger et al., 2012, table 3). This table clearly demonstrates that these traits, similar to other multitrait instruments (e.g., the NEO-PI-R; Marsh et al., 2010) do not show simple structure, with several $D S M-5$ traits showing substantial crossloadings. Emotional Lability, for example, is a relatively pure marker of the Negative Affectivity dimension, whereas Restricted Affectivity, has an almost equally high loading in the derivation sample on the Detachment factor. Likewise, Irresponsibility and Impulsivity primarily load the broad Disinhibition factor, whereas Rigid Perfectionism loads $>|.30|$ on three of the five $D S M-5$ trait dimensions.

\section{Psychometric Analyses}

Factor congruence coefficients were computed for the NEO-PI-3 after Procrustes rotation (McCrae, Zonderman, Bond, Costa, \& Paunonen, 1996) toward the NEO-PI-R normative structure observed in the United States (Costa \& McCrae, 1992). Factor congruencies between the PID-5 
structure obtained after exploratory factor analysis, using the CF-Equamax oblique rotation in MPlus (Muthén \& Muthén, 1998-2010), and the structures reported by Krueger et al. (2012) and Wright et al. (2012) were computed using $\mathrm{R}$ (http://www.personality-project.org/R/html/factor.congruence.html). Identical rotation procedures adopted by Krueger et al. (2012) and Wright et al. (2012) were used to ensure comparability.

Exploratory factor analysis followed by $\mathrm{CF}$-equamax oblique rotation was used to investigate the common factor structure of the NEO-PI-3 domains and facets and the PID-5 scales, respectively. An oblique rotation was preferred given the correlated nature of psychopathology measures. The minimum average partial test (Velicer, 1976) and parallel analysis were used to determine the number of factors to retain using the SPSS program proposed by O'Connor (2000).

\section{Results \\ Descriptives}

Descriptives of the main study variables are presented in Table 1. Since the NEO-PI-3 means are directly comparable with those of its parent inventory, NEO-PI-R normative data (Hoekstra et al., 1996) can be used to interpret the means. Given the overrepresentation of women in this sample, female Flemish/Dutch norms were used for positioning the present sample. The 30 -facet scale means correspond to stanine scores ranging between 3 (C3: Dutifulness and C5: Self-Discipline) and 7 (E5: Impulsiveness), with stanine scores of 4, 5, or 6 for the remaining 27 facet scales. Such findings suggest no major general differences between the current sample and a representative female sample of the general Flemish/Dutch population, with deviations in the expected direction for an undergraduate student population (see the somewhat lower average for Self-Discipline and the higher Impulsiveness scores). For the PID-5, no Flemish/Dutch normative data were available, preventing such comparison. Overall, the NEO-PI-3 domains and facets showed a near symmetrical distribution; PID-5 scales showed approximately symmetrical to moderately (positively) skewed distributions, suggesting more responses at the lower end of the scales (indicating an absence or fewer symptoms, in line with what could be expected for a student sample).

\section{Psychometric Properties of General and Maladaptive Traits}

Cronbach's alphas for the NEO-PI-3 facets ranged from .56 (O6: Openness to Values) to .86 (O6: Openness to Fantasy) with a median value of .78. The factor structure of the NEO-PI-3 showed congruency coefficients after
Table I. Scale Descriptives.

\begin{tabular}{|c|c|c|c|c|}
\hline Scale & Mean & $S D$ & Skewness & Kurtosis \\
\hline NEO-PI-3: Neuroticism & 152.14 & 22.39 & -0.04 & 0.15 \\
\hline NEO-PI-3: Extraversion & 160.13 & 20.21 & -0.22 & 0.60 \\
\hline NEO-PI-3:Openness & 172.54 & 18.71 & 0.05 & -0.19 \\
\hline NEO-PI-3:Agreeableness & 165.01 & 18.50 & -0.37 & 0.49 \\
\hline NEO-PI-3: Conscientiousness & 154.87 & 20.81 & -0.21 & -0.25 \\
\hline $\mathrm{NI}$ :Anxiety & 27.73 & 5.39 & -0.37 & 0.36 \\
\hline N2: Hostility & 23.05 & 4.45 & 0.20 & -0.03 \\
\hline N3: Depression & 26.69 & 5.59 & -0.11 & -0.34 \\
\hline N4: Self-Consciousness & 25.40 & 5.00 & -0.14 & 0.11 \\
\hline N5: Impulsiveness & 26.83 & 4.38 & 0.12 & -0.53 \\
\hline N6:Vulnerability & 22.45 & 5.12 & 0.16 & 0.19 \\
\hline EI:Warmth & 29.51 & 4.38 & -0.78 & 1.90 \\
\hline E2: Gregariousness & 26.96 & 5.77 & -0.51 & 0.09 \\
\hline E3:Assertiveness & 22.92 & 5.47 & 0.14 & 0.11 \\
\hline E4:Activity & 23.94 & 3.98 & 0.13 & -0.10 \\
\hline E5: Excitement-Seeking & 26.95 & 4.44 & -0.20 & -0.05 \\
\hline E6: Positive emotions & 29.85 & 4.94 & -.54 & 0.44 \\
\hline OI: Fantasy & 29.02 & 5.53 & -0.26 & -0.09 \\
\hline O2:Aesthetics & 28.92 & 5.49 & -0.30 & -0.31 \\
\hline O3: Feelings & 31.07 & 3.66 & -0.15 & -0.06 \\
\hline O4:Actions & 24.50 & 4.21 & .09 & -0.05 \\
\hline O5: Ideas & 28.07 & 5.73 & -0.01 & -0.44 \\
\hline O6:Values & 30.96 & 3.28 & 0.09 & 0.15 \\
\hline Al:Trust & 26.92 & 4.42 & -0.49 & 0.26 \\
\hline A2: Straightforwardness & 27.18 & 5.39 & -0.25 & -0.28 \\
\hline A3:Altruism & 30.65 & 3.58 & -0.59 & 1.04 \\
\hline A4: Compliance & 22.81 & 4.61 & 0.13 & 0.26 \\
\hline A5: Modesty & 28.30 & 5.03 & -0.41 & -0.01 \\
\hline A6:Tender-Mindedness & 29.15 & 3.77 & -0.33 & 0.35 \\
\hline $\mathrm{Cl}$ : Competence & 27.23 & 4.01 & -0.28 & -0.03 \\
\hline C2:Order & 24.04 & 5.36 & 0.08 & -0.07 \\
\hline C3: Dutifulness & 28.99 & 3.76 & -0.47 & 0.71 \\
\hline C4:Achievement-Striving & 26.22 & 4.86 & -0.31 & -0.14 \\
\hline C5: Self-Discipline & 23.68 & 4.98 & 0.09 & -0.45 \\
\hline C6: Deliberation & 24.72 & 5.14 & -0.15 & -0.70 \\
\hline PID-5: Emotional Lability & 1.67 & 0.54 & 0.03 & -0.35 \\
\hline PID-5:Anxiousness & 1.55 & 0.61 & 0.05 & -0.36 \\
\hline PID-5: Restricted Affectivity & 0.98 & 0.51 & 0.25 & -0.30 \\
\hline PID-5: Separation Insecurity & 1.52 & 0.59 & 0.09 & 0.02 \\
\hline PID-5: Hostility & 1.23 & 0.47 & 0.12 & 0.07 \\
\hline PID-5: Perseveration & 1.26 & 0.41 & 0.01 & 0.24 \\
\hline PID-5: Submissiveness & 1.30 & 0.53 & -0.23 & -0.41 \\
\hline PID-5:Withdrawal & 0.76 & 0.55 & 0.72 & 0.33 \\
\hline PID-5:Anhedonia & 0.92 & 0.52 & 0.72 & 0.21 \\
\hline PID-5: Depressivity & 0.88 & 0.57 & 0.85 & 0.61 \\
\hline PID-5: Intimacy Avoidance & 0.56 & 0.53 & 0.98 & 0.47 \\
\hline PID-5: Suspiciousness & 1.16 & 0.44 & 0.12 & 0.10 \\
\hline PID-5: Manipulativeness & 1.22 & 0.63 & -0.26 & -0.70 \\
\hline PID-5: Deceitfulness & 0.97 & 0.49 & 0.09 & -0.54 \\
\hline PID-5: Grandiosity & 0.68 & 0.50 & 0.60 & -0.11 \\
\hline PID-5:Attention Seeking & 1.22 & 0.51 & 0.11 & 0.12 \\
\hline PID-5: Callousness & 0.54 & 0.39 & 0.65 & -0.65 \\
\hline PID-5: Irresponsibility & 0.80 & 0.43 & 0.24 & 0.52 \\
\hline PID-5: Impulsivity & 1.22 & 0.57 & 0.15 & -0.32 \\
\hline PID-5: Rigid Perfectionism & 1.24 & 0.53 & 0.21 & -0.25 \\
\hline PID-5: Distractibility & 1.32 & 0.53 & -0.04 & -0.05 \\
\hline PID-5: Risk Taking & 1.32 & 0.50 & -0.09 & -0.34 \\
\hline $\begin{array}{l}\text { PID-5: Unusual Beliefs and } \\
\text { Experiences }\end{array}$ & 0.75 & 0.60 & 0.79 & 0.39 \\
\hline PID-5: Eccentricity & 1.19 & 0.65 & 0.13 & -0.42 \\
\hline PID-5: Perceptual Dysregulation & 0.83 & 0.47 & 0.39 & -0.62 \\
\hline
\end{tabular}

Note. PID-5 = Personality Inventory for DSM-5; NEO-PI-3 = Revised NEO Personality Inventory. Flemish/Dutch NEO-PI-3 items are scored on a 5-point Likert-type scale, from I to 5; PID-5 scales are scored from 0 to 3 , and item means are presented. 
Procrustes rotation with the American normative NEOPI-R structure of .94, .97, .94, .96, and .97 for Neuroticism, Extraversion, Openness to Experience, Agreeableness, and Conscientiousness, respectively. A five-factor solution explained $61.29 \%$ of the variance and there was a clear drop in eigenvalues after the fifth factor $(6.36,3.89,3.55$, $2.66,1.93,1.04, .93, .87, \ldots$ ). Congruence coefficients for the NEO-PI-3 facets were all greater than .90, except for E5: Excitement Seeking (.83), O6: Openness to Values (.88), and A1: Trust (.89).

Cronbach's alpha coefficients for the PID-5 scales ranged from .75 (Submissiveness and Suspiciousness) to .95 (Eccentricity) with a median value of .86. The PID-5 structure showed congruence coefficients toward an independent sample of U.S. undergraduates $(N=2,461)$ examined by Wright et al. (2012) of .97, .95, .97, .93, and .94 for Negative Affectivity, Detachment, Antagonism, Disinhibition, and Psychoticism, respectively. Factor congruence coefficients for the structure reported by Wright et al. with the derivation sample of Krueger et al. (2012) were as follows: 97 (Negative Affectivity), .96 (Detachment), .98 (Antagonism), .93 (Disinhibition), and .95 (Psychoticism). The current study obtained congruence coefficients with the general population derivation sample of Krueger et al. of .97, .96, $.93, .82$, and .97 for the dimensions of Negative Affectivity, Detachment, Antagonism, Disinhibition, and Psychoticism, respectively. Across comparisons, each coefficient exceeds the cutoff replication (Haven \& ten Berge, 1977), with one subthreshold value for Disinhibition, comparing the U.S. derivation general population sample with the current Flemish undergraduate sample. This somewhat lower congruence specifically for Disinhibition and specifically for Flemish undergraduates compared with a U.S. general population sample may be attributable to these samples being from different populations, noting that congruencies exceeding .93 were obtained for all domains between the undergraduate sample of Wright et al. and the current undergraduate sample, as well as between the derivation sample and the Wright et al. sample. Given that all other congruence coefficients exceeded .93, it may also simply be a chance finding, given the number of coefficients that were computed, or the modest sample size of the present research.

An exploratory factor analysis (followed by equamax oblique rotation with maximum likelihood as the estimator) of the 25 PID-5 scales showed reasonable fit indices $\left(\chi^{2}=\right.$ 503.592, $d f=185 ; p<.000$; comparative fit index $[\mathrm{CFI}]=$ .90; Tucker-Lewis index $[\mathrm{TLI}]=.84$; root mean square error of approximation [RMSEA] $=.085$, and standardized root mean residual $[\mathrm{SRMR}]=.036$ ) for a five-factor structure and nonacceptable indices for a three- or fourfactor solution, hereby confirming the proposed structure by Krueger et al. (2012). The loading parameter estimates for the standardized five-factor solution are described in Table 3. A visual comparison with the loading matrix of the
Table 2. Pattern Coefficients for an Exploratory Factor Analysis on the PID-5 Traits in the Derivation Sample.

\begin{tabular}{|c|c|c|c|c|c|}
\hline & I & II & III & IV & $\mathrm{V}$ \\
\hline Emotional Lability & .69 & & & & \\
\hline Anxiousness & .56 & & & & \\
\hline Restricted Affectivity & -.54 & .48 & & & \\
\hline Separation Insecurity & .47 & & & & \\
\hline Hostility & .38 & & .34 & & \\
\hline Perseveration & .34 & & & & .33 \\
\hline Submissiveness & .27 & & & & \\
\hline Withdrawal & & .68 & & & \\
\hline Anhedonia & & .61 & & .38 & \\
\hline Depressivity & .33 & .46 & & .34 & \\
\hline Intimacy Avoidance & & .44 & & & \\
\hline Suspiciousness & & .37 & & & \\
\hline Manipulativeness & & & .76 & & \\
\hline Deceitfulness & & & .59 & & \\
\hline Grandiosity & & & .55 & & \\
\hline Attention Seeking & & & .51 & & \\
\hline Callousness & & & .48 & .38 & \\
\hline Irresponsibility & & & & .57 & \\
\hline Impulsivity & & & & .57 & \\
\hline Rigid Perfectionism & .31 & & .37 & -.38 & \\
\hline Distractibility & & & & .34 & \\
\hline Risk Taking & & & & .31 & \\
\hline $\begin{array}{l}\text { Unusual Beliefs and } \\
\text { Experiences }\end{array}$ & & & & & .76 \\
\hline Eccentricity & & & & & .63 \\
\hline $\begin{array}{l}\text { Perceptual } \\
\text { Dysregulation }\end{array}$ & & & & & .58 \\
\hline
\end{tabular}

Note. PID-5 = Personality Inventory for DSM-5. Only factor loadings $>|.30|$ are reported. $N=1,128$. Table adapted from Krueger, Derringer, Markon, Watson, and Skodol (20I2, table 3, p. 8); I = Negative Affectivity, $\mathrm{II}=$ Detachment, $\mathrm{III}=$ Antagonism, IV = Disinhibition, $\mathrm{V}=$ Psychoticism.

American derivation sample (Table 2) shows that both the primary and the cross-loadings are well replicated. For example, Risk Taking loaded again across different $D S M-5$ dimensions, whereas Restricted Affectivity had a primary loading on Negative Affectivity and a substantial secondary loading on Detachment. Overall, higher primary loadings were observed in the present sample, with smaller crossloadings than in the U.S. derivation sample. For example, Separation Insecurity and all Psychoticism scales had higher primary loadings, whereas Callousness had a higher primary loading on Antagonism, with smaller cross-loadings on the other factors.

\section{Joint Factor Structure}

A joint exploratory factor analysis of the FFM domains and the 25 PID-5 traits showed decreasing eigenvalues of 8.01, $4.17,3.00,2.59,1.89,1.35,0.81,0.76,0.74$, and .64 for the 
Table 3. Pattern Coefficients From Exploratory Factor Analysis: Five-Factor Solution (Current Study).

\begin{tabular}{|c|c|c|c|c|c|}
\hline & 1 & II & III & IV & V \\
\hline Emotional Lability & .68 & .00 & .05 & .06 & .17 \\
\hline Anxiousness & .62 & .39 & .05 & -.09 & .19 \\
\hline Restricted Affectivity & -.53 & .46 & .16 & .04 & .18 \\
\hline Separation Insecurity & .69 & -.02 & .02 & .01 & .03 \\
\hline Hostility & .32 & .11 & .57 & .06 & .00 \\
\hline Perseveration & .35 & .25 & .12 & -.01 & .31 \\
\hline Submissiveness & .33 & .14 & -.02 & .08 & .01 \\
\hline Withdrawal & -.23 & .68 & .09 & -.22 & .24 \\
\hline Anhedonia & .17 & .78 & .03 & -.06 & .09 \\
\hline Depressivity & .35 & .70 & -.10 & .13 & .18 \\
\hline Intimacy Avoidance & -.33 & .47 & -.01 & -.02 & .23 \\
\hline Suspiciousness & .27 & .40 & .28 & -.09 & .17 \\
\hline Manipulativeness & .10 & -.27 & .70 & .13 & .13 \\
\hline Deceitfulness & .09 & -.04 & .76 & .21 & .07 \\
\hline Grandiosity & -.15 & -.05 & .60 & -.16 & .27 \\
\hline Attention Seeking & .13 & -.29 & .46 & -.03 & .25 \\
\hline Callousness & -.24 & .27 & .73 & .08 & -.01 \\
\hline Irresponsibility & -.02 & .26 & .33 & .53 & .04 \\
\hline Impulsivity & .15 & -.06 & .07 & .71 & .06 \\
\hline Rigid Perfectionism & .20 & .08 & .18 & -.57 & .27 \\
\hline Distractibility & .18 & .37 & -.01 & .45 & .14 \\
\hline Risk Taking & -.29 & -.26 & .03 & .56 & .28 \\
\hline $\begin{array}{l}\text { Unusual Beliefs and } \\
\text { Experiences }\end{array}$ & .02 & -.17 & .06 & -.05 & .86 \\
\hline Eccentricity & -.08 & .19 & .12 & .13 & .62 \\
\hline $\begin{array}{l}\text { Cognitive and } \\
\text { Perceptual } \\
\text { Dysregulation }\end{array}$ & .09 & .12 & -.05 & .19 & .81 \\
\hline
\end{tabular}

Note. $I$ = Negative Affectivity; II = Detachment; III = Antagonism; IV = Disinhibition; $\mathrm{V}=$ Psychoticism. Loadings $>|.30|$ are given in boldface.

first 10 factors pointing to retain five or six factors. Minimum average partial analysis suggested retaining six factors, but parallel analysis (with increasing number of random data sets) consistently pointed to retain five. The first five eigenvalues from the actual data were larger than the corresponding first five 95th percentile random data eigenvalues, whereas the sixth eigenvalue was lower.

The results of the five-factor solution, after equamax oblique rotation (MPlus) are described in Table 4. Inspection of the factor loading matrix shows that the NEO-PI-3 domain scales had the highest loadings on four of the five dimensions, with the Neuroticism and Openness domains positively loading factors together with facets mainly marking the PID-5 Negative Affectivity and Psychoticism factors, respectively, and the Agreeableness, Extraversion, and Conscientiousness domains marking the opposite poles of the factors loaded by the majority of the Antagonism, Detachment, and Disinhibition PID-5 facets, respectively. A six-factor solution, presented in Table 5 , produces very
Table 4. Factor Loading Matrix of NEO-PI-3 Domains and PID-5 Facets: Five-Factor Solution.

\begin{tabular}{|c|c|c|c|c|c|}
\hline & I & II & III & IV & V \\
\hline Emotional Lability & .72 & -.16 & .03 & .14 & .07 \\
\hline Anxiousness & .73 & .20 & .03 & .21 & -.01 \\
\hline Restricted Affectivity & -.43 & .48 & .17 & .28 & .06 \\
\hline $\begin{array}{l}\text { Separation } \\
\text { Insecurity }\end{array}$ & .67 & -.19 & .00 & .01 & -.01 \\
\hline Hostility & .39 & -.01 & .65 & -.03 & .07 \\
\hline Perseveration & .43 & .14 & .11 & .34 & -.01 \\
\hline Submissiveness & .37 & -.02 & -.10 & .09 & .07 \\
\hline Withdrawal & -.08 & .78 & .12 & .25 & -.08 \\
\hline Anhedonia & .30 & .69 & .07 & .12 & .10 \\
\hline Depressivity & .45 & .47 & -.09 & .27 & .21 \\
\hline Intimacy Avoidance & -.23 & .48 & -.05 & .33 & .04 \\
\hline Suspiciousness & .35 & .30 & .30 & .21 & -.07 \\
\hline Manipulativeness & .05 & -.35 & .63 & .22 & -.01 \\
\hline Deceitfulness & .07 & -.17 & .70 & .19 & .14 \\
\hline Grandiosity & -.12 & .03 & .59 & .28 & -.20 \\
\hline Attention Seeking & .12 & -.35 & .42 & .27 & -.07 \\
\hline Callousness & -.20 & .22 & .77 & .07 & .08 \\
\hline Irresponsibility & -.04 & .06 & .34 & .17 & .53 \\
\hline Impulsivity & .06 & -.32 & .11 & .19 & .58 \\
\hline Rigid Perfectionism & .34 & .19 & .14 & .23 & -.63 \\
\hline Distractibility & .19 & .14 & .03 & .21 & .55 \\
\hline Risk Taking & -.37 & -.34 & .07 & .39 & .32 \\
\hline $\begin{array}{l}\text { Unusual Beliefs and } \\
\text { Experiences }\end{array}$ & .04 & -.06 & .06 & .78 & -.09 \\
\hline Eccentricity & .00 & .19 & .15 & .63 & .14 \\
\hline $\begin{array}{l}\text { Perceptual } \\
\text { Dysregulation }\end{array}$ & .14 & .10 & -.02 & .79 & .16 \\
\hline Neuroticism & .74 & .25 & -.03 & -.01 & .30 \\
\hline Extraversion & -.09 & -.88 & .03 & .12 & -.04 \\
\hline Openness & -.14 & -.26 & -.23 & .53 & .00 \\
\hline Agreeableness & .03 & -.11 & -.87 & .11 & -.06 \\
\hline Conscientiousness & -.05 & -.07 & .01 & .06 & -.95 \\
\hline
\end{tabular}

Note. PID-5 = Personality Inventory for DSM-5; NEO-PI-3 = Revised NEO Personality Inventory. I = Negative Affectivity-Neuroticism; II = Detachment-Extraversion; III = Antagonism-Agreeableness; IV = Psychoticism-Openness; $\mathrm{V}=$ Disinhibition-Conscientiousness. Loadings $>|.30|$ are given in boldface.

similar factors as reported for the five-factor solution with an additional first factor that is positively loaded by Anxiousness (.37), Separation Insecurity (.43), Perseveration (.51), Submissiveness (.63), Depressivity (.37), Irresponsibility (.32), Rigid Perfectionism (.36) and negatively by Openness to Experience (-.49), with no other scales having loadings greater than $|.30|$ on this factor. The fifth factor in this solution was loaded by Openness to Experience (.76), the three Psychoticism facets and Risk Taking (.38), with no other PID-5 scales loading $>|.30|$ on this factor. Fit indices, however, favored the six-factor solution. For the five-factor solution, the $\mathrm{CFI}=.88$ and the TLI $=.82$, with $\mathrm{RMSEA}$ values of 
Table 5. Factor Loading Matrix of NEO-PI-3 Domains and PID-5 Facets: Six-Factor Solution.

\begin{tabular}{|c|c|c|c|c|c|c|}
\hline & I & II & III & IV & V & VI \\
\hline Emotional Lability & .06 & -.08 & .73 & .07 & .20 & .05 \\
\hline Anxiousness & .37 & .19 & .58 & .01 & .15 & -.02 \\
\hline Restricted Affectivity & .28 & .37 & -.56 & .10 & .17 & .08 \\
\hline Separation Insecurity & .43 & -.24 & .49 & -.05 & -.10 & -.02 \\
\hline Hostility & .05 & .02 & .39 & .67 & .01 & .06 \\
\hline Perseveration & $.5 \mathrm{I}$ & .06 & .22 & .04 & .20 & -.02 \\
\hline Submissiveness & .63 & -.16 & .09 & -.24 & -.11 & .07 \\
\hline Withdrawal & .06 & .77 & -.10 & .14 & .25 & -.08 \\
\hline Anhedonia & .26 & .65 & .19 & .06 & .07 & .10 \\
\hline Depressivity & .37 & .44 & .31 & -.11 & .20 & .20 \\
\hline Intimacy Avoidance & .26 & .40 & -.34 & -.10 & .23 & .04 \\
\hline Suspiciousness & .29 & .27 & .24 & .28 & .15 & -.07 \\
\hline Manipulativeness & .10 & -.36 & .02 & .58 & .23 & -.01 \\
\hline Deceitfulness & .22 & -.22 & -.01 & .62 & .16 & .14 \\
\hline Grandiosity & .19 & -.03 & -.19 & .54 & .23 & -.19 \\
\hline Attention Seeking & .21 & -.39 & .04 & .37 & .23 & -.07 \\
\hline Callousness & .21 & .13 & -.29 & .71 & .01 & .09 \\
\hline Irresponsibility & .32 & -.04 & -.16 & .26 & .07 & .54 \\
\hline Impulsivity & .09 & -.33 & .04 & .08 & .17 & .58 \\
\hline Rigid Perfectionism & .36 & .14 & .18 & .11 & .13 & -.63 \\
\hline Distractibility & .18 & .12 & .14 & .01 & .17 & .54 \\
\hline Risk Taking & -.07 & -.34 & -.32 & .06 & .38 & .32 \\
\hline $\begin{array}{l}\text { Unusual Beliefs and } \\
\text { Experiences }\end{array}$ & .20 & -.06 & -.01 & .05 & .70 & -.09 \\
\hline Eccentricity & .05 & .22 & .02 & .17 & .64 & .13 \\
\hline $\begin{array}{l}\text { Perceptual } \\
\text { Dysregulation }\end{array}$ & .30 & .09 & .06 & -.03 & .68 & .15 \\
\hline Neuroticism & .18 & .29 & .68 & .00 & .00 & .28 \\
\hline Extraversion & -.04 & -.87 & -.08 & -.01 & .12 & -.04 \\
\hline Openness & -.49 & -.09 & .10 & -.13 & .76 & -.01 \\
\hline Agreeableness & .14 & -.13 & -.04 & -.92 & .02 & -.05 \\
\hline Conscientiousness & .03 & -.08 & -.09 & .00 & .04 & -.95 \\
\hline
\end{tabular}

Note. PID-5 = Personality Inventory for DSM-5; NEO-PI-3 = Revised NEO Personality Inventory. I = Difficult to label; II = Detachment-Extraversion; III = Negative Affectivity-Neuroticism; IV = Antagonism-Agreeableness; $\mathrm{V}=$ Psychoticism-Openness $; \mathrm{VI}=$ Disinhibition-Conscientiousness. Loadings $>|.30|$ are given in boldface.

.09 (confidence interval [CI] of .084 and .098) and an SRMR value $=.04$, whereas the CFI $=.91$ and the $\mathrm{TLI}=.86$, with RMSEA values of .08 (CI of .073 and .088) and an SRMR value $=.03$ for the six-factor solution .

A similar analysis at the facet level largely confirmed the previous picture with some notable deviations. Inspection of Table 6 shows that several PID-5 Negative Affectivity facets together with five of the six NEO-PI-3 Neuroticism facets, except N5: Impulsiveness, primarily and positively loaded the first factor. The first factor was further primarily loaded by Depressivity, Suspiciousness and negatively loaded by O4: Openness to Actions. The second factor was positively loaded by all Extraversion facets, O3: Openness to Feelings, A1: Trust, A3: Altruism, and negatively by Restricted Affectivity, and all Detachment scales (although Depressivity
Table 6. Factor Loading Matrix of NEO-PI-3 Facets and PID-5 Facets: Five-Factor Solution.

\begin{tabular}{|c|c|c|c|c|c|}
\hline & I & $\|$ & III & IV & $\mathrm{V}$ \\
\hline Emotional Lability & .72 & .25 & .11 & .18 & -.04 \\
\hline Anxiousness & .80 & -.11 & .07 & .18 & .03 \\
\hline Restricted Affectivity & -.34 & -.63 & .11 & .19 & -.10 \\
\hline Separation Insecurity & .66 & .31 & .09 & -.06 & .01 \\
\hline Hostility & .37 & .00 & .68 & .00 & -.06 \\
\hline Perseveration & .50 & -.15 & .16 & .26 & .03 \\
\hline Submissiveness & .41 & .08 & -.07 & -.01 & -.10 \\
\hline Withdrawal & .06 & -.83 & .03 & .22 & .09 \\
\hline Anhedonia & .43 & -.61 & .01 & .06 & -.11 \\
\hline Depressivity & .57 & -.40 & -.10 & .25 & -.19 \\
\hline Intimacy Avoidance & -.11 & -.55 & -.10 & .26 & -.04 \\
\hline Suspiciousness & .43 & -.30 & .28 & .17 & .07 \\
\hline Manipulativeness & .03 & .23 & .67 & .28 & .03 \\
\hline Deceitfulness & .08 & .06 & .71 & .23 & -.13 \\
\hline Grandiosity & -.07 & -.17 & .59 & .22 & .21 \\
\hline Attention Seeking & .09 & .22 & .49 & .25 & .09 \\
\hline Callousness & -.16 & -.33 & .72 & .03 & -.10 \\
\hline Irresponsibility & .00 & -.12 & .36 & .14 & -.53 \\
\hline Impulsivity & .00 & .28 & .18 & .27 & -.56 \\
\hline Rigid Perfectionism & .40 & -.21 & .17 & .08 & .61 \\
\hline Distractibility & .24 & -.14 & .04 & .24 & -.52 \\
\hline Risk Taking & -.44 & .15 & .12 & .45 & -.33 \\
\hline $\begin{array}{l}\text { Unusual Beliefs and } \\
\text { Experiences }\end{array}$ & .13 & -.10 & .17 & .64 & .12 \\
\hline Eccentricity & .08 & -.35 & .17 & .61 & -.11 \\
\hline $\begin{array}{l}\text { Perceptual } \\
\text { Dysregulation }\end{array}$ & .25 & -.23 & .08 & .65 & -.15 \\
\hline NI:Anxiety & .78 & -.05 & .01 & .03 & -.03 \\
\hline N2:Angry hostility & .48 & -.11 & .42 & -.03 & -.15 \\
\hline N3: Depression & .68 & -.22 & -.15 & .13 & -.27 \\
\hline N4: Self-Consciousness & .57 & -.29 & -.21 & -.06 & -.11 \\
\hline N5: Impulsiveness & .33 & .35 & .04 & .15 & -.41 \\
\hline N6:Vulnerability & .71 & -.04 & -.10 & -.11 & -.34 \\
\hline EI:Warmth & .03 & .80 & -.12 & .14 & .12 \\
\hline E2: Gregariousness & -.04 & .74 & .02 & -.15 & -.20 \\
\hline E3:Assertiveness & -.23 & .34 & .32 & .14 & .29 \\
\hline E4:Activity & -.18 & .30 & .22 & .18 & .22 \\
\hline $\begin{array}{l}\text { E5: Excitement- } \\
\text { Seeking }\end{array}$ & -.30 & .44 & .09 & .40 & -.20 \\
\hline E6: Positive emotions & -.25 & .68 & .04 & .15 & .03 \\
\hline OI: Fantasy & -.08 & .09 & -.06 & .62 & -.12 \\
\hline O2:Aesthetics & -.05 & .01 & -.29 & .50 & .12 \\
\hline O3: Feelings & .23 & .45 & -.10 & .44 & .17 \\
\hline O4:Actions & -.46 & .II & -.12 & .36 & -.17 \\
\hline O5: Ideas & -.21 & -.14 & -.10 & .58 & .24 \\
\hline O6:Values & -.10 & .10 & -.23 & .38 & .02 \\
\hline Al:Trust & -.14 & .49 & -.35 & -.01 & .01 \\
\hline A2: Straightforwardness & .04 & -.03 & -.75 & -.12 & .05 \\
\hline A3:Altruism & .16 & .48 & -.44 & .19 & .24 \\
\hline A4: Compliance & -.04 & -.15 & -.61 & .02 & .00 \\
\hline A5: Modesty & .07 & -.04 & -.66 & -.07 & -.12 \\
\hline A6:Tender-Mindedness & .11 & .27 & -.59 & .24 & .07 \\
\hline $\mathrm{Cl}$ : Competence & -.35 & .21 & .19 & -.03 & .62 \\
\hline C2:Order & .05 & .05 & .09 & -.15 & .65 \\
\hline C3: Dutifulness & .16 & -.02 & -.33 & .04 & .71 \\
\hline $\begin{array}{l}\text { C4:Achievement } \\
\text { Striving }\end{array}$ & -.03 & .05 & .14 & .19 & .72 \\
\hline C5: Self-Discipline & -.20 & .13 & -.02 & .00 & .70 \\
\hline C6: Deliberation & .06 & -.30 & -.08 & -.18 & .67 \\
\hline
\end{tabular}

Note. PID-5 = Personality Inventory for DSM-5; NEO-PI-3 = Revised NEO Personality Inventory. I = Negative Affectivity-Neuroticism; II = Extraversion-Detachment; III = Antagonism-Agreeableness; IV = Openness-Psychoticism; $\mathrm{V}=$ Conscientiousness-Disinhibition. Loadings $>|.30|$ are given in boldface. 
and Suspiciousness primarily loaded the first Negative Affect factor). The third factor was primarily positively loaded by all PID-5 Antagonism scales, Hostility, and negatively by all Agreeableness facets, although A1: Trust and A3: Altruism had their highest loadings on the second factor. The fourth factor was positively loaded by all Openness facets, although O3: Openness to Feelings and O4: Openness to Actions primarily loaded a different factor, supplemented with primary loadings by Risk Taking and all Psychoticism scales. Finally, the fifth factor was primarily loaded by all Conscientiousness scales, negatively by N5: Impulsiveness and further by all Disinhibition scales but Risk Taking that had its primary loading on the fourth factor.

The six-factor solution described in Table 7 produced clearly identifiable Negative Affectivity, Detachment, Antagonism, and Constraint factors. One factor was almost exclusively primarily loaded by all Openness facets, with loadings of $.31, .31, .23, .35$, and -.35 for Unusual Beliefs and Experiences, Eccentricity, Perceptual Dysregulation, Risk Taking, and Submissiveness respectively, with no other PID-5 scales loading $>|.30|$ on this factor, whereas the remaining factor was primarily loaded by Eccentricity (.56), Perceptual Dysregulation (.71), Unusual Beliefs and Experiences (.63), supplemented by 17 PID-5 scales with factor loadings $>|.30|$ on this factor. Fit indices for the NEO-PI-3 and PID-5 facet analyses were unacceptable for both the five- and the six-factor solutions. For the five-factor solution, the CFI $=.75$ and the TLI $=.69$, with RMSEA values of .09 (CI of .087 and .094) and an SRMR value = .05 , whereas the CFI $=.80$ and the TLI $=.75$, with $\mathrm{RMSEA}$ values of .08 (CI of .078 and .086) and an SRMR value $=$ .04 for the six-factor solution.

\section{Discussion}

The current study examined the replicability of the proposed DSM-5 trait model (Krueger et al., 2012) and explored the common structure of two major measures proposed to assess personality pathology, that is, the NEO-PI-3 and the PID-5. The latter has been proposed to operationalize the DSM-5 trait structure, whereas the NEO inventories have been proposed to assess general traits, including disordered personality (Costa \& McCrae, 2010). Given their prominence as major (Widiger \& MullinsSweatt, 2009) operationalizations of personality pathology, an examination of their position toward each other and their joint structure was timely and warranted.

The current work is, to our knowledge, the first reporting on the psychometric properties of a foreign-language version of the PID-5. The results showed strongly comparable internal consistency coefficients and structural comparability with American undergraduate samples (Hopwood et al., 2012; Wright et al., 2012) and the derivation general population sample (Krueger et al., 2012). From a range of
Table 7. Factor Loading Matrix of NEO-PI-3 Facets and PID-5 Facets: Six-Factor Solution.

\begin{tabular}{|c|c|c|c|c|c|c|}
\hline & I & II & III & IV & V & VI \\
\hline Emotional Lability & .75 & .08 & .15 & .10 & -.04 & .15 \\
\hline Anxiousness & .66 & -.08 & .02 & .39 & .07 & -.10 \\
\hline Restricted Affectivity & -.53 & -.33 & .00 & .49 & -.08 & -.17 \\
\hline Separation Insecurity & .56 & .36 & .04 & .19 & .07 & -.24 \\
\hline Hostility & .40 & -.13 & .73 & .00 & -.06 & -.03 \\
\hline Perseveration & .34 & -.02 & .09 & .51 & .07 & -.10 \\
\hline Submissiveness & .21 & .32 & -.19 & .40 & -.02 & -.35 \\
\hline Withdrawal & -.05 & -.76 & .00 & .33 & .08 & .01 \\
\hline Anhedonia & .27 & -.50 & -.04 & .33 & -.08 & -.22 \\
\hline Depressivity & .42 & -.29 & -.16 & .49 & -.15 & -.11 \\
\hline Intimacy Avoidance & -.27 & -.31 & -.19 & .49 & -.02 & -.08 \\
\hline Suspiciousness & .29 & -.21 & .23 & .40 & .10 & -.12 \\
\hline Manipulativeness & -.01 & .27 & .62 & .31 & .03 & .12 \\
\hline Deceitfulness & -.01 & .16 & .63 & .39 & -.11 & -.01 \\
\hline Grandiosity & -.17 & -.06 & .53 & .35 & .22 & .00 \\
\hline Attention Seeking & .03 & .29 & .44 & .32 & .10 & .07 \\
\hline Callousness & -.28 & -.15 & .64 & .30 & -.08 & -.22 \\
\hline Irresponsibility & -.10 & .06 & .28 & .36 & -.50 & -.14 \\
\hline Impulsivity & .04 & .30 & .17 & .21 & -.55 & .14 \\
\hline Rigid Perfectionism & .24 & -.11 & .12 & .33 & .65 & -.15 \\
\hline Distractibility & .19 & -.09 & .01 & .31 & -.51 & .03 \\
\hline Risk Taking & -.37 & .20 & .13 & .24 & -.36 & .35 \\
\hline $\begin{array}{l}\text { Unusual Beliefs and } \\
\text { Experiences }\end{array}$ & .05 & .00 & .13 & .63 & .11 & .31 \\
\hline Eccentricity & .02 & -.30 & .15 & .56 & -.14 & .31 \\
\hline $\begin{array}{l}\text { Perceptual } \\
\text { Dysregulation }\end{array}$ & .14 & -.09 & .03 & .71 & -.14 & .23 \\
\hline NI:Anxiety & .68 & -.08 & -.02 & .21 & .01 & -.13 \\
\hline N2:Angry hostility & .55 & -.31 & .50 & -.11 & -.17 & .01 \\
\hline N3: Depression & .58 & -.21 & -.18 & .29 & -.24 & -.10 \\
\hline N4: Self-Consciousness & .45 & -.25 & -.25 & .17 & -.07 & -.23 \\
\hline N5: Impulsiveness & .44 & .16 & .10 & -.06 & -.43 & .21 \\
\hline N6:Vulnerability & .66 & -.09 & -.10 & .04 & -.30 & -.21 \\
\hline El:Warmth & .09 & .77 & -.12 & .00 & .13 & .20 \\
\hline E2: Gregariousness & -.03 & .85 & -.03 & -.05 & -.16 & -.17 \\
\hline E3:Assertiveness & -.09 & .16 & .40 & -.18 & .24 & .35 \\
\hline E4:Activity & -.17 & .32 & .21 & .11 & .21 & .16 \\
\hline $\begin{array}{l}\text { E5: Excitement- } \\
\text { Seeking }\end{array}$ & -.24 & .48 & .09 & .21 & -.22 & .33 \\
\hline E6: Positive emotions & -.12 & .58 & .07 & -.12 & .01 & .31 \\
\hline OI: Fantasy & .06 & -.10 & .01 & .18 & -.20 & .68 \\
\hline O2:Aesthetics & .07 & -.15 & -.21 & .11 & .06 & .57 \\
\hline O3: Feelings & .41 & .18 & .00 & -.01 & .11 & .60 \\
\hline O4:Actions & -.33 & .05 & -.07 & .02 & -.22 & .44 \\
\hline O5: Ideas & -.11 & -.28 & -.03 & .18 & .16 & .62 \\
\hline O6:Values & .08 & -.14 & -.12 & -.09 & -.06 & .58 \\
\hline Al:Trust & -.06 & .46 & -.33 & -.14 & .01 & .11 \\
\hline A2: Straightforwardness & .04 & .01 & -.73 & -.12 & .07 & -.08 \\
\hline A3:Altruism & .18 & .48 & -.45 & .09 & .25 & .19 \\
\hline A4: Compliance & -.17 & .07 & -.7 I & .25 & .04 & -.17 \\
\hline A5: Modesty & .04 & .03 & -.67 & -.02 & -.10 & -.10 \\
\hline A6:Tender-Mindedness & .21 & .15 & -.52 & -.03 & .04 & .33 \\
\hline $\mathrm{Cl}$ : Competence & -.28 & .15 & .23 & -.19 & .58 & .16 \\
\hline C2: Order & .01 & .06 & .08 & -.08 & .66 & -.09 \\
\hline C3: Dutifulness & .13 & -.05 & -.30 & .00 & .70 & .08 \\
\hline C4:Achievement Striving & -.04 & .05 & .15 & .12 & .71 & .17 \\
\hline C5: Self-discipline & -.22 & .18 & -.03 & -.01 & .70 & .04 \\
\hline C6: Deliberation & -.01 & -.29 & -.08 & -.08 & .67 & -.13 \\
\hline
\end{tabular}

Note. PID-5 = Personality Inventory for DSM-5; NEO-PI-3 = Revised NEO Personality Inventory. I = Negative Affectivity-Neuroticism; II = Extraversion-Detachment; III = Antagonism-Agreeableness; IV = Psychoticism-general personality pathology; $\mathrm{V}=$ Conscientiousness-Disinhibition; $\mathrm{VI}=$ Openness. Loadings $>|.30|$ are given in boldface. 
independent studies, there is now converging evidence that the structure among the 25 PID-5 scales is best represented by a five-dimensional model, with Negative Affectivity, Detachment, Antagonism, Disinhibition, and Psychoticism as the higher order factors. Replicability is important because it demonstrates that the psychometric properties of the PID-5 are preserved when administration instructions and item set are carefully translated (and checked via an independent back translation) in a foreign language. Although the DSM taxonomy is developed by the American Psychiatric Association, it has a major impact across the globe, and should hence be easily transferable. Moreover, the demonstration of a stable positioning of maladaptive traits under the higher order factors is a prerequisite to be useful to diagnose a trait-specified personality disorder (www.dsm5.org). One proposed criterion to diagnose a trait-specified personality disorder is that elevated scores on one or more personality higher order trait domains, or specific facets within domains, considering all the five domains, must be present. This criterion thereby necessitates a robust maladaptive trait structure, with a stable positioning of $D S M-5$ facets within the factor space.

An examination of the joint structure of the 25 PID-5 traits with either the FFM domains or their facets shows a five- or a six-dimensional structure, that is easily interpretable from the perspective of the FFM, extended to assess both general (via the NEO-3) and maladaptive (via the PID-5) personality traits (Krueger \& Eaton, 2010). Comparable with other studies on complex trait structures, fit indices for the five- and the six-factor solutions were inadequate (Hopwood \& Donnellan, 2010). When considering five dimensions, the inclusion of domain or facet markers of the NEO marginally affects the resulting factor pattern, with, respectively, 21 and 20 out of 25 PID- 5 scales loading primarily on the same factor as the one that was conceptually closest in the DSM-5 model. The results for the five-factor solution are in line with Thomas et al. (2012), although there are also some differences. Restricted Affectivity had almost equal loadings on Negative Affectivity and Detachment, whereas it almost exclusively loaded the Detachment factor in Thomas et al. (2012). Likewise, Impulsivity equally loaded the Openness and Conscientiousness factor in Thomas et al. but had only a substantive loading on Conscientiousness in our sample. Callousness had a strong loading on the AntagonismAgreeableness factor in our study, whereas it also loaded on this factor and the Detachment-Extraversion factor in Thomas et al. Finally, the Psychoticism Perceptual Dysregulation and Unusual Beliefs scales had secondary loadings on the Detachment-Extraversion component in Thomas et al. but not in our work.

Extracting six factors illustrates that there is a clear factor primarily loaded by Psychoticism facets and Openness to Experience, whereas the sixth factor was loaded by a number of PID-5 scales and secondarily by Openness to Experience.
The analyses at the NEO-PI-3 facet level, however, show more a bifurcation between all psychoticism facets loading high on the fourth factor, together with cross-loadings $(>|.30|)$ of 17 of the remaining 22 PID-5 scales, with a separate sixth Openness factor cross-loaded by Psychoticism facets. The bottom line from these analyses is that when NEO domains or facets are considered in a five-factor space, then Openness and Psychoticism facets load together. A six-factor solution however, shows more a bifurcation between Openness and Psychoticism scales, especially when NEO-facets are included in the analysis. The Openness to Experience domain seems more connected with the Psychoticism scales than its facets. The findings of the six-factor solution are intriguing and demonstrate the complexities in the Openness domain. The absolute fit indices got worse with more variables, that is, the PID-5 and NEO-PI-3 facet analyses produced worse indices than the FFM domains and PID-5 scales' analyses, suggesting that these phenomena should be studied further in larger samples.

Our results are much in line with those arguing that the FFM is a model accommodating traits to describe general and disordered personality (Costa \& McCrae, 2010; Widiger \& Mullins-Sweatt, 2009). Each factor is further loaded by a mixture of general and maladaptive traits, with PID-5 traits generally marking the socially evaluative negative and the NEO facets marking the evaluative positive side of the dimensions, except for those loading the Negative Affectivity/Neuroticism and the Psychoticism/Openness to Experience factors that are oriented similarly. In this respect, the current findings, together with those reported by Thomas et al. (2012), illustrate how the FFM is a unifying framework for understanding both adaptive and maladaptive personality, and how different assessment instruments complement each other in assessing various parts of the broader FFM framework (Costa \& McCrae, 2010; Krueger \& Eaton, 2010).

The current findings further shed light on the necessity of the "fifth of the FFM," that is the Openness dimension, to describe personality pathology. Proponents of the FFM have consistently argued that also Openness is important to understand personality pathology (Piedmont, Sherman, Sherman, Dy-Liacco, \& Williams, 2009). The current study underscores this position, showing that the Openness domain or the majority of its facets loaded a separate factor together with the PID-5 scales of Unusual Beliefs and Experiences, Perceptual Dysregulation, and Eccentricity when a five-factor solution was considered. The results reported for the six-factor solutions, on the other hand, are illustrative of the complex relations between Openness (facets) and Psychoticism (facets).

Alternatively, the joint factor structure can be also interpreted from a PSY-5 hierarchical perspective, similarly assumed to embrace normal personality and personality disorders (Harkness et al., 2012). Taking this angle, there is clear 
evidence from the current research for a separate Psychoticism factor, distinct from Negative Affectivity/Neuroticism, with the remaining general and maladaptive traits further subsumed under an Aggressiveness/Agreeableness, a Detachment/ Positive Affectivity-Extraversion, and a Conscientiousness/ Constraint factor, respectively. The current work illustrates how the FFM and the PSY-5 models converge as overarching models to accommodate general and maladaptive traits.

There are also limitations that should be kept in mind when evaluating the present findings. The sample consisted of undergraduates; although not uncommon in structural research, our findings need replication not only in the general population but also in heterogeneous groups of inpatients/outpatients. The DSM-5 trait model is meant to describe traits that are indicative of specific personality disorder types or, if the patient is not an exact match to one and only one disorder type, the traits delineating the features of the Personality Disorder-Trait Specified diagnosis. The distribution of these traits in undergraduate samples is likely to be different from patient groups, though personality problems are not absent in students, and there are a range of important studies of personality disorders conducted on student samples (e.g., the Longitudinal Study of Personality Disorders; Lenzenweger, 2006). Moreover, the kind of structural analyses conducted in our study is sensitive to outliers, which may be more prevalent in clinical samples, underscoring the utility of a student sample for a first exploratory description. Nevertheless, the PID-5 was constructed to assess Criterion B of dysfunctional personality (www.dsm5.org), and it is unlikely that a student sample taps a sufficient amount of dysfunctional personality variance relative to a clinical sample. The present study hence primarily described covariation and structural overlap at the more general level of personality functioning, and should be extended and replicated with studies using samples showing more clinical variation. For example, it remains to be demonstrated whether the joint loadings of the PID-5 Psychoticism and the NEO Openness facets on a single factor considering a five-factor solution can be replicated in clinical samples. In a similar vein, also six-factor solutions should be further considered in clinical and larger samples to examine whether Openness' core, its facets and Psychoticism form a single or more distinct dimensions. Ultimately, the DSM-5 trait model is intended "to describe the personality characteristics of all patients, whether they have a personality disorder or not" (www.dsm5.org), so research in nonpatient groups is certainly useful as a first benchmark, though the generalization of findings may be constrained and should be complemented by research in clinical samples in future research. Moreover, our sample was primarily female, and it is well known that there are substantial gender differences in personality pathology prevalence rates (Trull, Jahng, Tomko, Wood, \& Sher, 2010) and mean personality trait scores (Costa, Terracciano, \&
McCrae, 2001). Borderline pathology, strongly related to Neuroticism, is observed more frequently in females, and females have on average higher scores on Neuroticism. It is difficult, however, to speculate about how such mean differences and prevalence rates may have affected the present correlational research.

A second limitation is that both assessments are selfdescriptions introducing common method bias. An eloquent feature of trait measures is that knowledgeable others, such as partners, parents, or adult children, can supplement selfdescriptions (Keulen-De-Vos et al., 2011). The incremental validity and utility of other ratings is an underutilized and underresearched topic in clinical professional assessment practice and should be carefully explored in future research (Connelly \& Ones, 2010; South, Oltmanns, Johnson, \& Turkheimer, 2011).

A final constraint has to do with the PID-5 as an operationalization to assess the DSM-5 trait model, that is, the PID-5 was developed under the auspices of the American Psychiatric Association. Our current understanding is that the American Psychiatric Association intends to make this inventory freely available (as described in Krueger et al., 2012), but important professional issues still require discussion. For example, in rendering a formal DSM-5 personality disorder diagnosis, to get reimbursement from insurance companies for therapy, for example, how fungible are other inventories with the PID-5? The current results suggest that the PID-5 and the NEO-3 are very closely aligned empirically, suggesting that various inventories can and should be used to assess DSM-5 trait constructs. Nevertheless, additional work with other systems (e.g., the PSY-5, as operationalized in the Minnesota Multiphasic Personality Inventory-2; Harkness et al., 2012) and discussion of the use of other specific instruments for the clinical assessment of DSM-5 personality constructs will be important as the field transitions to the DSM-5 system.

From a theoretical point of view, the present findings support the validity of a hierarchical conceptualization of traits in which specific general and maladaptive traits are subsumed under the umbrella of a common set of five to six major dimensions of personality (Anderson et al., 2013; Harkness et al., 2012; Markon et al., 2005; Thomas et al., 2012). Such a framework may serve as a structurally valid model to examine psychopathology grounded in personality, including Axis-I psychopathology (De Bolle, Beyers, De Clercq, \& De Fruyt, 2012; Krueger, 2005; Krueger \& Eaton, 2010). The literature on FFM Axis-I relationships (Trull \& Sher, 1994; Widiger \& Trull, 1992) and the current work have underscored that the FFM can serve as the overarching framework to achieve such goals.

From an assessment perspective, the current work provided additional support for the DSM-5 trait model's construct validity and has underscored the psychometric 
properties of its accompanying inventory. The present findings further suggest that the NEO measures can be usefully supplemented with the PID-5 if the goal is to describe both the general and more maladaptive poles of the five-factor space. Stepp et al. (2012) recently demonstrated how a set of different personality measures, including the NEO-PI-R, the Schedule for Nonadaptive and Adaptive Personality, and Cloninger's Temperament and Character Inventory (Cloninger, Przybeck, Svrakic, \& Wetzel, 1994) were better able to assess the full range of personality differences observable across five major dimensions of personality. Using item response theory analyses, these authors demonstrated that the items from the different inventories had considerable variability in the item and test information derived from each inventory for the different underlying dimensions, suggesting the use of multiple measures in conjunction to achieve a more accurate description of the patient. The present findings encourage similar integrative research between the NEOPI-R/3 and the PID-5 item sets, preferably conducted on data obtained from mixed normal and clinical samples to assure enough variation across all dimensions.

Whereas the work by Hopwood et al. (2012) and Wright et al. (2012) already urged clinicians and assessment psychologists in the United States to evaluate the PID-5 for various clinical applications, the present work is the first showing that the psychometric properties of the PID-5 are preserved in a different language, encouraging practitioners in other language groups to examine the PID-5's clinical merits. An important open question for practitioners is how general and maladaptive trait measures can be integrated in current assessment practice, and how to avoid redundancy, given the overlap that was demonstrated in the present research. Our design, however, did not allow us to study the incremental validity of the $D S M-5$ traits over the NEO-PI-3, given the absence of a clinically useful criterion measure. Costa and McCrae (2010) have argued that a general trait description should be customary in assessment procedures, eventually augmented with the assessment of more pathological traits. Our study has shown that operationalizations of leading general and maladaptive trait measures converge into a common factor structure that may serve an integrative purpose to better understand pathology across multiple assessment instruments, as well as across DSM Axis I and Axis II.

\section{Declaration of Conflicting Interests}

The first author receives royalties for the Dutch NEO-PI-3. The authors are unaware of any other affiliation, funding, or financial holdings that might be perceived as affecting the objectivity of this research.

\section{Funding}

The authors received no financial support for the research, authorship, and/or publication of this article.

\section{Note}

1. With "experimental item set" we refer to the development phase of the Flemish/Dutch NEO-PI-3 item set, and not to experimentally manipulated NEO-PI-R items to make them more clinically relevant like Edmundson et al. (2011) have done for example.

\section{References}

American Psychiatric Association. (2000). Diagnostic and statistical manual of mental disorders (4th ed.-Text revision). Washington, DC: Author.

Anderson, J. L., Sellbom, M., Bagby, R. M., Quilty, L. C., Veltri, C. O. C., Markon, K. E., \& Krueger, R. F. (2013). On the convergence between PSY-5 domains and PID-5 domains and facets: Implications for assessment of DSM-5 personality traits. Assessment. Advance online publication. doi:10.1177/1073191112471141

Clark, L. A. (1993). Manual for the Schedule for Non-adaptive and Adaptive Personality (SNAP) Minneapolis: University of Minnesota Press.

Clark, L. A. (2007). Assessment and diagnosis of personality disorder: Perennial issues and an emerging reconceptualization. Annual Review of Psychology, 58, 227-257.

Cloninger, C. R., Przybeck, T. R., Svrakic, D. M., \& Wetzel, R. D. (1994). The Temperament and Character Inventory (TCI): A guide to its development and use. St. Louis, MO: Center for Psychobiology and Personality, Washington University.

Connelly, B. S., \& Ones, D. S. (2010). Another perspective on personality: Meta-analytic integration of observers' accuracy and predictive validity. Psychological Bulletin, 136, 1092-1122.

Costa, P. T., \& McCrae, R. R. (1992). Revised NEO Personality Inventory and Five-Factor Inventory professional manual. Odessa, FL: Psychological Assessment Resources.

Costa, P. T., \& McCrae, R. R. (2010). Bridging the gap with the five-factor model. Personality Disorders: Theory, Research, and Treatment, 1, 127-130.

Costa, P. T., Terracciano, A., \& McCrae, R. R. (2001). Gender differences in personality traits across cultures: Robust and surprising findings. Journal of Personality and Social Psychology, 81, 322-331.

De Bolle, M., Beyers, W., De Clercq, B., \& De Fruyt, F. (2012). General personality and psychopathology in referred and nonreferred children and adolescents: An investigation of continuity, pathoplasty and complication models. Journal of Abnormal Psychology, 121, 958-970. doi:10.1037/a0027742

De Fruyt, F., De Bolle, M., McCrae, R. R., Terracciano, A., \& Costa, P. T. (2009). Assessing the universal structure of personality in early adolescence: The NEO-PI-R and NEO-PI-3 in 24 cultures. Assessment, 16, 301-311.

De Fruyt, F., De Clercq, B. J., van de Wiele, L., \& Van Heeringen, K. (2006). The validity of Cloninger's psychobiological model versus the five-factor model to predict DSM-IV personality disorders in a heterogeneous psychiatric sample: Domain facet 
and residualized facet descriptions. Journal of Personality, 74, 479-510.

De Fruyt, F., Mervielde, I., Hoekstra, H. A., \& Rolland, J.-P. (2000). Assessing adolescents' personality with the NEO PI-R. Assessment, 7, 329-345.

Edmundson, M., Lynam, D. R., Miller, J. D., Gore, W. L., \& Widiger, T. A. (2011). A five-factor measure of schizotypal personality traits. Assessment, 18, 321-334

Haigler, E. D., \& Widiger, T. A. (2001). Experimental manipulation of NEO-PI-R items. Journal of Personality Assessment, 77, 339-358.

Harkness, A. R., Finn, J. A., McNulty, J. L., \& Shields, S. M. (2012). The Personality Psychopathology-Five (PSY-5): Recent constructive replication and assessment literature review. Psychological Assessment, 24, 432-443.

Harkness, A. R., \& McNulty, J. L. (1994). The personality psychopathology five (PSY-5): Issues from the pages of a diagnostic manual instead of a dictionary. In S. Strack \& M. Lorr (Eds.), Differentiating normal and abnormal personality (pp. 291-315). New York, NY: Springer.

Harkness, A. R., McNulty, J. L., \& Ben-Porath, Y. S. (1995). The Personality Psychopathology Five (PSY-5): Constructs and MMPI-2 scales. Psychological Assessment, 7, 104-114.

Haven, S., \& ten Berge, J. M. F. (1977). Tucker's coefficient of congruence as a measure of factorial invariance: An empirical study. Groningen, Netherlands: University of Groningen.

Hoekstra, H. A., \& De Fruyt, F. (2013). NEO-PI-3 Persoonlijkheidsvragenlijst [NEO-PI-3 personality inventory]. Manuscript in preparation.

Hoekstra, H. A., Ormel, J., \& De Fruyt, F. (1996). NEO PI-R en NEO-FFI: Big Five Persoonlijkheidsvragenlijsten [NEO PI-R en NEO-FFI: Big Five Personality Inventories]. Lisse, Netherlands: Swets \& Zeitlinger.

Hopwood, C. J., \& Donnellan, M. B. (2010). How should the internal structure of personality inventories be evaluated? Personality and Social Psychology Review, 14, 332-346.

Hopwood, C. J., Thomas, K. M., Markon, K. E., Wright, A. G. C., \& Krueger, R. F. (2012). DSM-5 personality traits and DSMIV personality disorders. Journal of Abnormal Psychology, 121, 424-432. doi:10.1037/a0026656

Keulen-De-Vos, M., Bernstein, D. P., Clark, L. A., Arntz, A., Lucker, T. P. C., \& de Spa, E. (2011). Patient versus informant reports of personality disorders in forensic patients. Journal of Forensic Psychiatry \& Psychology, 22, 52-71.

Krueger, R. F. (2005). Continuity of axes I and II: Toward a unified model of personality, personality disorders, and clinical disorders. Journal of Personality Disorders, 19, 233-261.

Krueger, R. F., Derringer, J., Markon, K. E., Watson, D., \& Skodol, A. E. (2012). Initial construction of a maladaptive personality trait model and inventory for DSM-5. Psychological Medicine, 42, 1879-1890. doi:10.1017/S0033291711002674.

Krueger, R. F., \& Eaton, N. R. (2010). Personality traits and the classification of mental disorders: Toward a more complete integration in DSM-5 and an empirical model of psychopathology. Personality Disorders: Theory, Research, and Treatment, 1, 97-118.

Lenzenweger, M. F. (2006). The longitudinal study of personality disorders: History, design, considerations, and initial findings. Journal of Personality Disorders, 20, 645-670.

Livesley, W. J. (1990). Dimensional Assessment of Personality Pathology-Basic Questionnaire. Vancouver, Canada: University of British Columbia.

Lynam, D. R., Gaughan, E. T., Miller, J. D., Miller, D. J., MullinsSweatt, S., \& Widiger, T. A. (2011). Assessing the basic traits associated with psychopathy: Development and validation of the elemental psychopathy assessment. Psychological Assessment, 23, 108-124.

Markon, K. E., Krueger, R. F., \& Watson, D. (2005). Delineating the structure of normal and abnormal personality: An integrative hierarchical approach. Journal of Personality and Social Psychology, 88, 139-157.

Marsh, H. W., Lüdtke, O., Muthén, B., Asparouhov, T., Morin, A. J. S., Trautwein, U., \& Nagengast, B. (2010). A new look at the big five factor structure through exploratory structural equation modeling. Psychological Assessment, 22, 471-491.

McCrae, R. R., Costa, P. T., \& Martin, T. A. (2005). The NEOPI-3: A more readable revised NEO Personality Inventory. Journal of Personality Assessment, 84, 261-270.

McCrae, R. R., Zonderman, A. B., Bond, M. H., Costa, P. T., \& Paunonen, S. V. (1996). Evaluating replicability of factors in the revised NEO personality inventory: Confirmatory factor analysis versus Procrustes rotation. Journal of Personality and Social Psychology, 70, 552-566.

Miller, J. D., Bagby, R. M., Pilkonis, P. A., Reynolds, S. K., \& Lynam, D. R. (2005). A simplified technique for scoring DSM-IV personality disorders with the five-factor model. Assessment, 12, 404-415.

Miller, J. D., Lynam, D. R., Rolland, J. P., De Fruyt, F., Reynolds, S. K., Pham-Scottez, A., \& Bagby, M. (2008). Scoring the DSM-IV personality disorders using the Five-Factor Model: Development and validation of normative scores for North American, French and Dutch-Flemish samples. Journal of Personality Disorders, 22, 433-450.

Morey, L. C., Gunderson, J. G., Quigley, B. D., Shea, M. T., Skodol, A. E., McGlashan, T. H., \& Zanarini, M. C. (2002). The representation of Borderline, Avoidant, Obsessive-Compulsive, and Schizotypal Personality Disorders by the fivefactor model. Journal of Personality Disorders, 16, 215-234.

Mullins-Sweatt, S. N., Jamerson, J. E., Samuel, D. B., Olson, D. R., \& Widiger, T. A. (2006). Psychometric properties of an abbreviated instrument of the five-factor model. Assessment, 13, 119-137.

Muthén, L. K., \& Muthén, B. O. (1998-2010). MPlus user's guide (6th ed.). Los Angeles, CA: Muthén \& Muthén.

O'Connor, B. P. (2000). SPSS and SAS programs for determining the number of components using parallel analysis and Velicer's MAP test. Behavior Research Methods Instruments \& Computers, 32, 396-402. 
Piedmont, R. L., Sherman, M. F., Sherman, N. C., Dy-Liacco, G. S., \& Williams, J. E. G. (2009). Using the five-factor model to identify a new personality disorder domain: The case for experiential permeability. Journal of Personality and Social Psychology, 96, 1245-1258.

Samuel, D. B., \& Widiger, T. A. (2008). A meta-analytic review of the relationships between the five-factor model and DSMIV-TR personality disorders: A facet level analysis. Clinical Psychology Review, 28, 1326-1342.

Saulsman, L. M., \& Page, A. C. (2004). The five-factor model and personality disorder empirical literature: A meta-analytic review. Clinical Psychology Review, 23, 1055-1085.

South, S. C., Oltmanns, T. F., Johnson, J., \& Turkheimer, E. (2011). Level of agreement between self and spouse in the assessment of personality pathology. Assessment, 18, 217-226.

Stepp, S. D., Yu, L., Miller, J. D., Hallquist, M. N., Trull, T. J., \& Pilkonis, P. A. (2012). Integrating competing dimensional models of personality: Linking the SNAP, TCI and NEO using item response theory. Personality Disorders: Theory, Research, and Treatment, 3, 107-126.

Thomas, K. M., Yalch, M. M., Krueger, R. F., Wright, A. G. C., Markon, K. E., \& Hopwood, C. J. (2012). The convergent structure of DSM-5 personality trait facets and five-factor model trait domains. Assessment. Advance online publication. doi: $10.1177 / 1073191112457589$

Trull, T. J., Jahng, S., Tomko, R. L., Wood, P. K., \& Sher, K. J. (2010). Revised NESARC personality disorder diagnoses: Gender, prevalence, and comorbidity with substance dependence disorders. Journal of Personality Disorders, 24, 412-426.

Trull, T. J., \& Sher, K. J. (1994). Relationship between the 5-factor model of personality and axis-I disorders in a nonclinical sample. Journal of Abnormal Psychology, 103, 350-360.

Velicer, W. F. (1976). Determining number of components from matrix of partial correlations. Psychometrika, 41, 321-327.

Watson, D., Clark, L. A., \& Chmielewski, M. (2008). Structures of personality and their relevance to psychopathology: II. Further articulation of a comprehensive unified trait structure. Journal of Personality, 76, 1545-1586.

Widiger, T. A., \& Costa, P. T., Jr. (2013). Personality disorders and the five-factor model of personality. Washington, DC: American Psychological Association.

Widiger, T. A., Costa, P. T., \& McCrae, R. R. (2002). A proposal for Axis II: Diagnosing personality disorders using the five-factor model. In P. T. Costa \& T. A. Widiger (Eds.), Personality disorders and the five-factor model of personality (2nd ed., pp. 431-456). Washington, DC: American Psychological Association.

Widiger, T. A., \& Mullins-Sweatt, S. N. (2009). Five-factor model of personality disorder: A proposal for DSM-V. Annual Review of Clinical Psychology, 5, 197-220.

Widiger, T. A., \& Simonsen, E. (2005). Alternative dimensional models of personality disorder: Finding a common ground. Journal of Personality Disorders, 19, 110-130.

Widiger, T. A., Simonsen, E., Sirovatka, P. J., \& Regier, D. A. (2006). Dimensional models of personality disorders: Refining the research agenda for DSM- $V$. Washington, DC: American Psychiatric Association.

Widiger, T. A., \& Trull, T. J. (1992). Personality and psychopathology -An application of the 5-factor model. Journal of Personality, 60, 363-393.

Widiger, T. A., \& Trull, T. J. (2007). Plate tectonics in the classification of personality disorder: Shifting to a dimensional model. American Psychologist, 62, 71-83.

Widiger, T. A., Trull, T. J., Clarkin, J. F., Sanderson, C., \& Costa, P. T. (2002). A description of the DSM-IV personality disorders with the five-factor model of personality. In P. T. Costa \& T. A. Widiger (Eds.), Personality disorders and the five-factor model of personality (2nd ed., pp. 89-99). Washington, DC: American Psychological Association.

Wright, A. G. C., Thomas, K. M., Hopwood, C. J., Markon, K. E., Pincus, A. L., \& Krueger, R. F. (2012). The hierarchical structure of the DSM-5 pathological personality traits. Journal of Abnormal Psychology, 121, 951-957. 